\title{
Design for authenticity: a new methodology for the NPD process in the luxury market
}

\author{
Romeo Bandinelli*, Chiara Pampaloni, Rinaldo Rinaldi \\ Department of Energy Engineering, University of Florence, Florence, ITALY \\ ${ }^{*}$ Corresponding Author: e-mail: romeo.bandinelli@unifi.it
}

\begin{abstract}
The luxury market is surely one of the areas most affected by the counterfeiting phenomenon. The presence of fake goods means a financial loss for companies, both in terms of reduced turnover, but also in terms of intangible losses (i.e. brand value reduction). This phenomenon led companies, in the last years, to ask their New Product Development (NPD) division if and how it was possible to develop unique products, difficult or even impossible to replicate, and how to help customers in the identification of authentic goods versus fake ones. The aim of this work is to answer these questions in a context characterized by a growing awareness of the authenticity guarantee and product integrity, combined with the need of traceability. The purpose of this paper is therefore to develop a qualitative and quantitative methodology, called Design for Authenticity (DfA), aimed to protect the authenticity of a product in all the stages of its life cycle, with a special regard to the aspects related to the authenticity of the product.
\end{abstract}

Keywords: luxury, new product development, methodology, counterfeiting, product value

DOI: http://dx.doi.org/10.4314/ijest.v5i2.12S

\section{Introduction}

During last years, the topic of the counterfeiting phenomenon has been widely discussed by practitioners and researchers and several papers regarding how new technologies, i.e. RFId, can be used in order to reduce it can be find. Focusing on the last years, it is possible to find both papers describing RFId applications and improvements (Lehtonen, 2007)(Periaswamy, 2011)(Rahman, 2012)(Yan, 2008)(Chen, 2007)(Lakafosis, 2010), than survey on the use of RFId tags against counterfeiting (Jeng et all, 2009). At the same time several papers have been wrote in order to explore the relationship among the value of the brand of a company and the profile of the buyers and on the determinant of purchasing intention (Amatulli and Guido, 2010)(Morley and McMahon, 2011), or on the role of innovation (Finn, 2011)(Moore and Stephen, 2010), or on the relationship among marketing and brand value (Fionda and Moore, 2009). Even if it is very difficult to analyse the heritage and its relationship between brand value and customer perception in a quantitative way, it is a matter of fact that the brand value is affected by the amount of fakes which is possible to find in the market, and by the perception of authenticity that a luxury product can transmit to the customer.

Despite the large quantity of paper that it is possible to find regarding these two topics describe above, our research showed that none of the paper analyses the relationship among the design, development and production processes of luxury companies and the possibility to generate counterfeiting products, and no one of the papers addressed the topic of defining a comprehensive approach, to be used since the beginning of the lifecycle of the product, in order to reduce and prevent the counterfeiting phenomenon.

The aim of this work is therefore to reduce this gap answering a research question which is "how to improve the New Product Development (NPD) process, in order to develop unique products, difficult or even impossible to replicate, and how to help customers in the identification of authentic goods versus fake ones". The purpose of this paper is therefore to develop a qualitative and quantitative methodology, called Design for Authenticity (DfA), aimed to protect the authenticity of a product in all the stages of its life cycle, in order to offer a guide to the NPD managers in choosing the best techniques to be adopted to protect intellectual 
property and combating the black market, according to the company's business strategies. In particular, it is addressed to firms which belong to the fashion industry, with specific regard to the clothing sector.

The main result of the application of the DfA is a complete redesign of the companies' business processes, to ensure the authenticity and integrity of the product, its traceability through the supply chain, create a major difficulty in the production of counterfeit goods and, at the same time, to allow an easy recognition of original items, in order to prevent their distribution through unauthorized channels.

The paper is structured as follow: section 2 introduce the theoretical background of the paper, focusing on the aspects related to the luxury industry, the counterfeiting phenomenon and how the product value can be calculated in fashion ware markets; section 3 analyze the fashion value chain, explaining how counterfeiting phenomenon take place since the NPD process; section 4 describes the methods and research context; section 5 describe the DfA methodology; section 6 explains its methods and tools; section 7 introduces its validation, while section 8 presents some conclusions.

\section{Theoretical background}

\subsection{The luxury Industry}

Luxury products are primarily purchased for their intangible value (Brun et al., 2008), which is composed by an emotional and a symbolic parts, rather than for their functional aspects. Usually luxury products have a strong artisan component, and their implementation is the result of the work of specialized personnel with skills difficult to reproduce.

Saviolo and Testa (Saviolo and Testa, 2005) classify the fashion markets defining five main market segments: couture, prêt-àporter, diffusion, bridge, and mass: from the first to the last one, the price of the sold product decreases, the number of sold units increases, whilst the quality level decreases. The higher segment called Couture is characterized by the high quality of the materials used and an high stylistic content. Products are often handmade and unique, and as such are characterized by an elevated price (e.g. Chanel, Dior). Following this segment we find the Prêt-à-porter, which is composed of products characterized by high quality and significant creative aspects; within this category, prices are very high. To be found in this segment both griffes and industrial brands. Critical success factors are linked to the brand image, innovation and product quality and due to this investments in advertising and communication are usually high for companies belonging to this sector. Lower in the classification is it possible to find the Diffusion (e.g. Emporio Armani, D\&G), Bridge and Mass market (i.e. Benetton) segments.

Our study will concern mainly with the first two segments, Couture and Prêt-à-porter which can be considered to be included in the Luxury market, even if some implications could be extended to the other segments.

\subsection{The market for counterfeit products}

Counterfeiting and piracy have become an international phenomena, with a significant impact on the economic and social field, modifying the equilibrium between supply and demand in the market. Even if it is difficult to calculate the entity of this phenomena, counterfeit goods move a turnover estimated in a range between 3,5 to 7 billion euro. As reported by the Indicam Insitute, in 2008 the $60 \%$ of the total turnover was related to clothing and fashion products (textiles, leather goods, footwear), while the other $40 \%$ was divided among watches, consumer goods, components and software (Indicam, 2010).

The word counterfeiting is generally referred to the illicit activity of copying and distributing false goods, trying to make them indistinguishable from the original ones.

According to the Agreement on Trade-related Aspects of Intellectual Property Rights (TRIPs Agreement), Annex 1C of the Marrakesh Agreement Establishing the World Trade Organization (WTO), signed in Marrakesh, Morocco on 15 April 1994, the counterfeiting phenomenon can be define as follow (WTO, 2004):

- "Counterfeit trademark goods" shall mean any goods, including packaging, bearing without authorization a trademark which is identical to the trademark validly registered in respect of such goods, or which cannot be distinguished in its essential aspects from such a trademark, and which thereby infringes the rights of the owner of the trademark in question under the law of the country of importation.

- "Pirated copyright goods" shall mean any goods which are copies made without the consent of the right holder or person duly authorized by the right holder in the country of production and which are made directly or indirectly from an article where the making of that copy would have constituted an infringement of a copyright or a related right under the law of the country of importation.

As well known, a trademark is a legally protected brand name and a distinctive sign or indicator used by an individual, a business organization, or other legal entities which identify that a product or a service is unique for the consumers. Especially in luxury fashion industry, the brand, and consequently its legal term trademark, is one of the key factor for the success of a company (Bruce et al., 2004). The brand contributes to the definition of an identity, to create an image, and every marketing strategy is strictly related with it. This way, a counterfeit product could generate, besides the economic damage, related to the turnover reduction, a loss of image and credibility, which may impacts on consumer confidence in the brand. In fact, the brand often identifies a design, but it is also a synonymous of exclusivity and implied warranty of quality and safety. All these features cannot be found in a counterfeit product, whilst the presence of fakes on the market can decrease customers for the brand. 
Coming to a customers' vision of this phenomenon, the reasons for the purchase of counterfeit goods are often linked to the desire of belonging to and identification with a particular social class. At the same time, many of these branded products are unreachable to most people due to their price, and they became a status symbol. The only way to obtain these products is to enter the counterfeit products market. Other reasons that move consumers towards counterfeit products are related to their economical convenience (i.e. the customer could buy the original product, but the fake one has a minor cost and no disadvantages) or transgression and snobbery.

In order to be exhaustive, it is important to highlight that not all consumers are aware of buying a counterfeit good: in addition to conscious shoppers, there are, albeit to a minor extent, people who buy fake products thinking to buy an original one. If the counterfeit good is well-made and hard to distinguish from the original, the consumer can be deceived by the seller and therefore be a victim of fraud.

Analyzing the typology of customers described above, in authors opinion it is important to divide the potential customers into two main categories. The first one regards people who would like to buy a luxury good, but are not able to buy it because of the high price. The second one includes people who can afford to buy a luxury product, but prefer to buy a fake one, because of economic advantages. These people can decide to buy the product on the white market, but also on the black or on the gray market. As said before, the value of a luxury product is composed mostly by an intangible value (emotional and symbolic). This intangible value can be reduced, or cancelled, from a counterfeited product, only if a specific condition is verified: if the fake product can be easily recognized. This way, an important aspect, which can impact on customers behavior, belonging to the second group, is the facility to identify authentic versus false products. On the other hand, this approach it is almost useless for people belonging to the first group. Because of the fact that they are not able to buy an original product, the only effect that it is possible to achieve is the reduction of the fake products on the market, but it is impossible to retrieve sales from this category.

\subsection{The protection of the intellectual property}

The protection of the intellectual property can be, for our purpose, synthesized in the activity of guaranteeing the authenticity of a product, where the concept of "authenticity" can be declined into three different aspects of intellectual property: (product) authenticity, integrity, traceability, as reported in Figure 1.

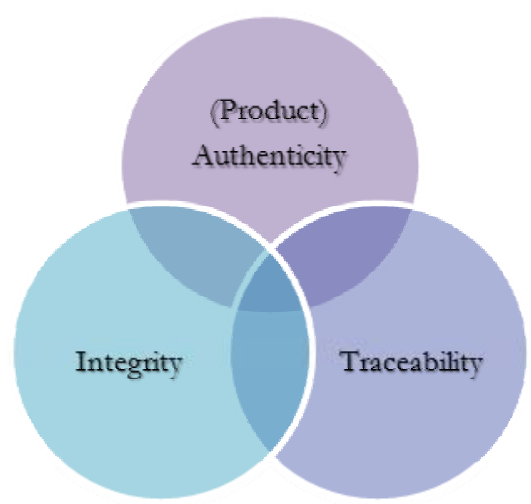

Figure 1 - Definition of authenticity - list of the three components

(Product) authenticity regards the assurance that the product is really what the company produces and on which puts its own mark. To ensure integrity means that the product has not been altered, damaged or tampered with in any way. In the end, the word traceability is referred to Track \& Trace: the first is meant to know the exact location of the product, while the second to know all the points in which it was and to check the consistency with those expected.

This definition of authenticity, extended to the three concepts listed above, is inspired by the publications of the AntiCounterfeiting Institute of Centromarca (INDICAM). Only a uniform protection of these three aspects will ensure an high protection against the counterfeiting phenomenon. Anti-counterfeiting technologies have been introduced in order to protect all of these aspects of the intellectual property, increasing the level of security of the supply chain, making more difficult to reproduce false products, and introducing new features, which aim is to make easily distinguishable fakes from original products. Despite this fact, in order to achieve the desired results, their introduction and use have to be planned from the beginning of the products lifecycle, starting from the NPD phase.

\subsection{Product Value in Fashion markets}

Another important aspect to define before starting to describe the DfA methodology is the definition of the product value in fashion markets, and the methodologies used in order to estimate it. Because of the fact that every investment has to be compared with the related revenues, in order to decide on the introduction of new technologies, companies have to estimate the return of the investment, which is strictly related to the value of the brand. This way, the brand positioning is a prerequisite in order to 
understand if and how introduce anti-counterfeiting technologies among the supply chain, in order to reduce false products and improve sales.

In literature is it possible to find many authors which have investigated the most appropriate way to assess the value of a brand: (Rajagopal, 2007), Keller (1993), Aaker (1996) have proposed models for the assessment of brand equity, identifying its components and defining specific brand metrics; other authors tried to adapt the model of the Balanced Scorecard to the measure of brand equity (Ambler, 2000; Trivedi et al., 2007; Logman, 2004). As a matter of fact, the value of a brand is linked to the overall value which is recognized to a product by its clients. This way, every company has the necessity, in order to determine the actual value, and consequently the price of a product, to understand the value of the brand. Brand equity can be measured indirectly by assessing the potential sources of brand equity, or directly through the potential outcomes that brand equity can provide. Measuring the sources means to study the perception of the brand that consumers have, therefore, analysing issues such as fame, power, perceived quality, associations raised (Keller, 1998).

According to (Porter, 1985), the value of a product is represented by the price that buyers are willing to pay for. When buying a product, the proposed price is compared by the customer with the perceived value or benefits that would result from the purchase of it (Winer, 2002). The perceived value is always relative, especially when dealing with a product linked to personal taste and intangible benefits such as fashion.

An interesting and complete definition of the value of the product is the one proposed by Schilling (2005), from which the definition of the value adopted in our methodology has been developed. The author deals with the value offered to customers from a new technology, arguing that it is determined by a combination of two elements: the value of the stand-alone technology and the value of network externalities.

The stand alone value that a technology provides to customers is determined by a number of factors, such as use functions, design, aesthetic qualities, ease of use and so on. On the other hand, the value of network externalities depends from the value generated by the installed customer base and by the availability of complementary goods.

Network externalities are positive, when the value of an asset for an individual increases with the increase of people who have the same asset, or with the increase of complementary products. To penetrate the market and replace an existing technology, the new technology has to be able to offer a higher overall value, radically improving the stand-alone utility and maintaining the compatibility with the installed base and the complementary goods already existing.

Moreover, Schilling (Schilling, 2005) distinguishes the concepts of actual value, expected value and perceived value. This classification takes into account another dimension of the value, linked to the dynamics of the market. In the evaluation of a new technology, users consider both objective and subjective information (perceptions), but also expectations for the future. In this sense, it is possible that the perceived and the expected values do not match the actual one. The proposed model, developed by the author for a generic product, in authors opinion can be extended to the case of a luxury product. The value of some clothes , or a purse, etc.. surely comes from the quality of materials and processes, often handmade (intrinsic value), but also by other factors, which can be bring back to the concept of externality. If on a traditional market externalities are related to the customers broad base, in fashion markets the popularity of the products and of the brand are strictly related to the probability of a product to be successful. Similarly, the availability of complementary goods can be interpreted as the availability of complementary services, from assistance from post-sale, but also the service and care provided in the store.

In this work, the overall value of a product, which is necessary in order to calculate profit changes due to the re-engineering of the product and consequently the reduction of counterfeit items sold, will be calculated by adding to the stand alone value the perceived value of externalities, using the survey based approach, as explained further in the paper.

\section{Counterfeiting and Fashion Value Chain}

\subsection{New Product Development (NPD) and Fashion markets}

New Product Development (NPD) assumes a particular relevance in the fashion system: in fact, fashion enterprises are supposed to react promptly to the dynamic market environment by creating more new products, with a very short Time To Market (TTM). Each season, designers and merchandisers develop hundreds of new products, in order to satisfy market needs. Within the luxury fashion markets, design process represents the activity with the major added value. This style excellence is usually achieved by keeping the design activities in-house, while collaborating with experienced external designers and stylists (Brun, 2008). NPD in fashion is not only the development of a new product, NPD in the fashion industry include processes of marketing research, trend analysis, merchandising, design and prototyping of final items. In these processes, information and knowledge are resources necessary for enabling the NPD team to create new concepts or upgrade existing products (Choy et al., 2008).

NPD is characterized by a large number of product revisions, in which the continuous interactions between designers, stylists and marketing functions take a long time and requires many iterations (Sen, 2008). Due to the seasonal nature of fashion products, NPD is characterized by high seasonal demand with a low percentage of carry over. The trend actually indicates an increase in the number of collections per year (usually at least four), with consequently a reduction not only for the TTM, but also for other activities of the value chain (i.e. the sale period, the production and the delivery of the final product).

In this context, many companies are trying to accelerate the NPD process, without defining clear strategies or without defining well-articulated processes, in order to protect the intellectual property of their products. This occurs mostly because fashion 
companies, driven by the need to do something quickly in a subject that is not well known and on which no data are available, demand the protection of their brand from external companies, or do not control the process from the beginning of the life cycle of the product itself.

Moreover, even if companies would like to include the intellectual property analysis in their NPD process, as the state of the art confirm, there is not specific methods or tools which are related to this area. There are methodologies that support the development of new products; making the process more efficient and effective, but none of them analyze the design of the products, in order to improve the authenticity of the product itself, into the three components defined above. Although every manager agrees on the importance of these issues, today there are no adopted methodologies among either practitioners or researches.

\subsection{Counterfeiting and Fashion Supply Chain Management (FSCM)}

The process of globalization, widely adopted by most of the fashion companies, decreasing the control on both raw materials and final products, has definitely caused a loss of control on the supply chain for the trademark holder.

Counterfeiting phenomenon are often originated by the existence of an extended supply chain, where manufacturers are located in different places and where the production is often made in subcontracting. Moreover, in the fashion industry, also the phases of the raw materials acquisition is offshored, making difficult the traceability of the product from the beginning of its cycle. This way, also the manufacturing, distribution and sale of counterfeit products can be distinct, often performed in different countries. Such behavior creates a complex and articulated chain. the consequence is that it is almost impossible to reach the organization that operates upstream. Often the visibility of the supply chain is very low, and the final seller knows little or nothing of the previous operations.

Going forward in the supply chain, in the fashion industry, is usual to find also the sampling phase outsourced or even offshored, especially towards countries in the Far East. This can easily become a risk for the company, because in this way technical specifications, bills of materials, information and product prototypes are shared with external actors from the first phases of the product lifecycle, long before the production and commercialization phases, exposing themselves to possible imitations.

Another problem connected with outsourcing and offshoring, in this case of the production phase, is the phenomenon of illegitimate overproduction by licensees, which represent the main cause of the parallel market. Products manufactured as factory overruns (which can take place every time the outsourced manufacturer exceeds the production quantity allowed by its licenser), are legally considered counterfeits, because they bear the trademark without permission of the owner. In other words, in this particular case, a counterfeit product have the same quality as the original, genuine product (Lehtonen et al., 2007)

With regard to the distribution and commercialization channels (Lehtonen et al., 2007), there are three main ways that counterfeit goods can follow.

- The principle certainly the network of illegal immigrants, managed by criminal organizations, which sells products throughout the territory (Ocse, 2009). These people represent only the last link of the chain and it's very difficult to go back to the main actors of these activities.

- The second form of commerce is made by traders, which sell counterfeit products in their exercise, often alongside the original ones. As previously written, in some cases, counterfeit goods are very difficult to distinguish from the originals, because they may be made by the same workshops. This fact make possible the existence of this channel of fake goods.

- Lastly, with the recent development of Internet and e-commerce, also the World Wide Web (WWW) has become a major vehicle for the spread of counterfeit goods.

Figure 2 reports a graphical representation of the classification of counterfeit products proposed above.
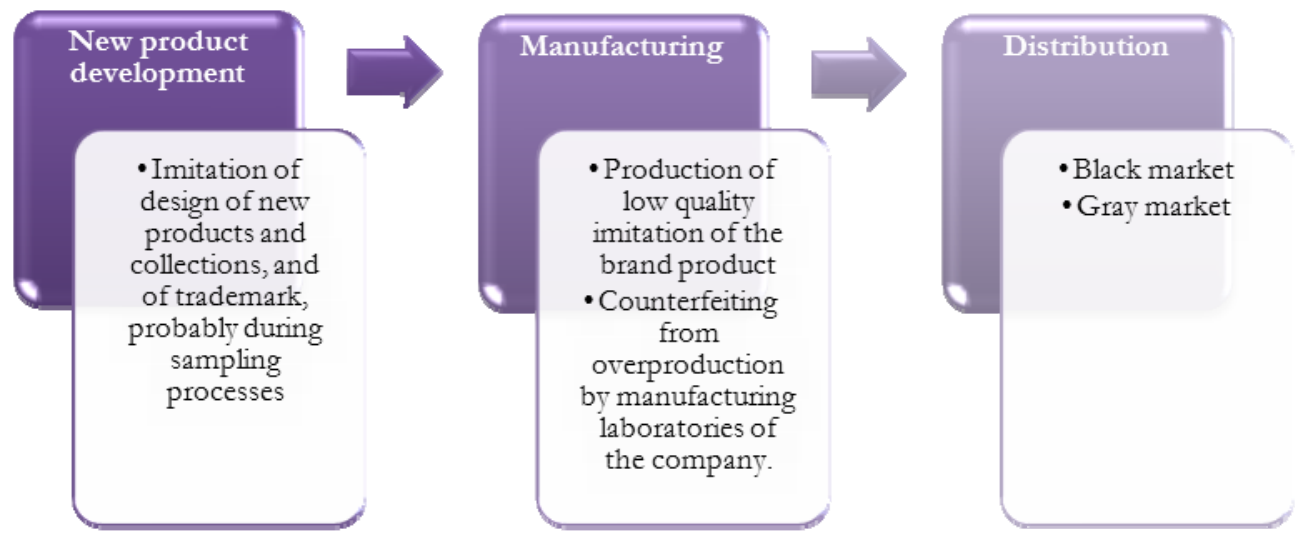

Figure 2 - Value chain and counterfeiting 
From a brand owner's perspective, distribution channels can be divided into licit supply chain (the so-called white market), and illegal ones (black and grey markets). Counterfeit products can be found on each of these markets (Lehtonen et al., 2007). Licit Supply Chain: The "White Market"

In the "white market", brand owners may choose to sell their products directly to authorized retailers or they may choose to sell through intermediaries, through one or multiple wholesalers. Retailers are authorized and certified by the brand owners and in some cases sell exclusively for one brand.

Illicit Market: The "Black Market"

The black market concerns the buying and selling of illegal products and services. Goods or services may be illegal because their sale is not permitted by the law (e.g., weapons and illegal drugs), or because it regards stolen products or items sold through illegal channels (in order to avoid tax payments or licensing requirements). This last case is the one concerning the counterfeiting market. In the black market, it's possible to find low-quality counterfeits, poor imitations that can be easily recognized as fake, but also high-quality counterfeits, whose quality is close or identical to the original products and that can fool even trained personnel. This kind of market, as previously wrote, can take place both on physical markets, than on the WWW.

The "Grey Market"

The "grey market" refers to the activity of selling original, authorized and branded products through unauthorized distribution channels. Grey market activities themselves are not illegal, but they can violate contracts between distributors, retailers and the brand owner. This market can become black and illegal only when the sold products are stolen or illegal.

Grey market can take place in flea markets, internet auctions, shopping sites, shopping booths, or even in shops. In some cases, authorized retailers that sell some original products to other retailers, usually operating in another area, in order to obtain an economic profit. This can happen when original products have different prices according to their distribution channels.

This model can be replicated upstream, among distributors, and in this case it represents one of the main sources for the grey market that is the parallel trade. Products lawfully marketed in the territory are sold through unauthorized channels. This may occur when for example, when the price of an item in a country is much higher than in another country (i.e. European versus Asiatic markets). Entrepreneurs buy the product where it is cheaper and import it legally to the final market and selling it at a price that generates a profit. The price of these products could be still lower than the market price, which is often imposed by the brand. The activity of controlling and reducing grey market is one of the activities which brands owners usually do systematically, even if it is very difficult to control.

\section{Methods and research context}

There are many different methods that can be applied in the development of new tools and methods for the NPD process, including surveys, case studies, action research, modeling and simulation (Forza, 2002; Voss et al., 2002; Coughlan and Coghlan, 2002; Bertrand and Fransoo, 2002).

The methodology followed for the development of this project is the Action Research. As the name suggests, action research is an approach to research aiming both at taking action and at creating knowledge or theory about the action. The goal is to make that action more effective while simultaneously building up a body of scientific knowledge.

The benefits of an action research study depend on its main characteristics: it investigates more than actions; it is participatory; it occurs simultaneously with the action; and it is a sequence of events and approaches used to solve problems, i.e. a longitudinal study. Furthermore, the action research is appropriate when the research is related to understanding the process of change, or its improvement and to learn about it (Coughlan and Coghlan,2002). Therefore, an action research design is the most appropriate research method because it develops a longitudinal study to review and update a company's New Product Development (NPD) process.

Action research comprises iterative cycles of gathering data, feeding them back to those concerned, analyzing the data, planning action, taking action and evaluating, leading to further data gathering and so on. At the same time, it is an application of scientific method of fact finding and experimentation to practical problems, requiring action solutions and involving the collaboration and cooperation of the action researchers and members of the organizational system. In this sense, members of the system which is being studied participate actively in the cyclical process (Gummesson, 2000). For example, to submit documents, data, reflections and progresses of the project to the control of the company, provides confirmation of the correct understanding of the processes and of the dynamics and allows the involvement of managers of the organization (Westbroook, 1994).

According to (Coughlan and Coghlan, 2002), the Action Research cycle comprises six main steps, that relate first to the data and then to the action, detailed as follows:

- Data gathering. Data could be gathered in different ways depending on the context, as operational statistics, financial accounts, marketing reports, but also observations, discussions and interviewing. In Action research, directly observable behaviour is an important source of data and provides the basis for the inquiry.

- Data feedback. The action researcher takes and feeds the gathered data to the client system, making it available for the analysis.

- Data analysis. Both the researcher and members of the organisation cooperate in doing data analysis; this collaborative approach represents a critical aspect, because their point of view about the subject is not impartial. 
- Action planning. Following from the analysis further action is planned, with the collaboration of organisation members, who have a deeper knowledge of the company and of the contest. In this phase, responsible for various activities and time schedules will be defined.

- Implementation. The organisation implements the planned action, making the desired changes.

- Evaluation. Evaluation involves reflecting on the outcomes of the action, both intended and unintended, a review of the process in order that the next cycle of planning and action may benefit from the experience of the completed cycle.

In the development of the DfA methodology, the Action Research approach has been followed, building the steps of the method, while simultaneously applying it to a business case. All the planning activities of the project was outlined and shared within a team, composed by researchers and members of the company.

The first phase has been devoted to the literature research on various topics and to the analysis of the context of the specific companies. This activity was also attended by some members of the company, that, have offered their knowledge, in particular about business processes. Data were collected and analyzed by the research laboratory, but the results were constantly shared with the team, rescheduling the project activities based on new considerations.

Every step of the methodology has been tested and continually improved through the team work, applying the theory to the company and verifying its validity, even taking a cue from the experience in the field of the members of the company.

\section{Description of the DfA methodology}

The methodology called "Design for Authenticity (DFA)" has been developed by the LOGistic process management and Intelligence Systems development LABoratory (LogisLab), which is an university laboratory located near Florence (Italy) working for several years in the area of logistic and supply chain management in the luxury sector and applied in a well know fashion Italian company belonging to the apparel industry..

The goal of this methodology is first to define a framework to normalize and redesign of the NPD process of fashion companies, in order to improve the protection of the authenticity of a product in all the stages of its life cycle. The methodology starts from a comprehensive analysis of the state of the art of anti-counterfeiting technologies and from the study of the knowledge of the company and of the context in which it operates. After that, a redesign of the all Value Chain and the product characteristics are proposed, evaluating both technical and management solutions and paying particular attention to the economic impact that these could have on the company.

In particular, the methodology is composed by the following steps:

\section{Study of product positioning and analysis of the Value Chain}

2. Assessment of the tools used by the company for authenticity, traceability, integrity.

3. Cross check of the results obtained in the previous step, in order to detect errors in tool use.

4. Evaluating the effectiveness of instruments for materials used, the finished product and in relation to the desired level of traceability on the Value Chain.

5. Business strategy analysis and anti-counterfeiting tools introduction evaluation.

6. Designing for the authenticity and integrity of product.

7. Designing for product traceability.

Hereafter, a detailed description of each step of the methodology and a short description of the results obtained in our case are reported.

Step 1: Study of product positioning and analysis of the Value Chain

The first phase of the methodology concerns the study of the positioning of the product in the market where the company operates. The goal of this step is to define the product position by analyzing the target of customers, the competitors and the product value (real and perceived), using a structured survey distributed among customers, sellers, distributors and retailers.

The main objective, as well as to define product positioning in the marketplace, is to assess how the introduction of initiatives regarding products' authenticity and anti-counterfeiting methods could affect customer perceptions and their buying behavior. In this way, these results could be translated into quantitative measures, and then in a measure of the economic impact of an investment for the protection of the brand.

At the same time, the knowledge of the internal structure of the company is essential in order to understand its business strategy and to identify all the causes of false phenomenon in the company market.

Another action of this step regards the understanding of the product Value Chain (VC). For this reason, a Business Process Mapping (BPM) has to be carried out, through a series of field visits and interviews conducted at every different levels of the supply chain. With the BPM analysis a snapshot of the As-Is state can be achieved and qualitative and quantitative measures, regarding both physical and information flows, can be defined. 
This preliminary stage is fundamental for the success of the application of this methodology, because it highlight company's vulnerabilities and permit to the company to understand where to stress the commitment in order to improve brand protection and product traceability, during the other steps of the methodology.

In our case, during the application of the step one, a business Processes Mapping Analysis (BPM)of the As-Is state of the company's processes has been carried out. The activity of collecting information and data was carried out through interviews, held at the headquarters of the company and involving managers from the Purchasing, Production, Logistics and IT functions. Managers were asked to describe the processes under their responsibility, highlighting the sequence of tasks, their responsibilities, the input and the output of each process, the Information and Communication Technologies (ICT) used, and the interaction with other business functions. The result of this step was represented by several documents and graphics, including a bi-dimensional graph, which dimensions were the arrays (Formal, Sportswear, Active wear) and (Mass, Bridge, Diffusion, Pret-a-Porter, Couture), where all the competitors of our company, previously identified, were positioned using a circular indicator). Moreover, using a survey based approach, a partition of the overall product value has been done according to the three components Intrinsic Value, Brand Value and Complementary services.

Step 2: Assessment of the tools used by the company for authenticity, traceability, integrity.

This second phase aims to assess all the existing tools used by the company to prevent the counterfeiting phenomenon, analyzing also the points of the value chain in which they are applied.

This way, an overview of the company regarding the technologies used can be done, and a comparison between them with those that could be potentially used in the sector can be achieved. This step also shows the level of coverage of the value chain, identifying the areas not fully covered by these instruments and thus not subjected to any control and protection.

In our case, this step has been carried out using a schema reported in Figure 1, where all the anti-counterfeiting technologies has been surveyed and classified according to the supply chain process where they has been implemented.

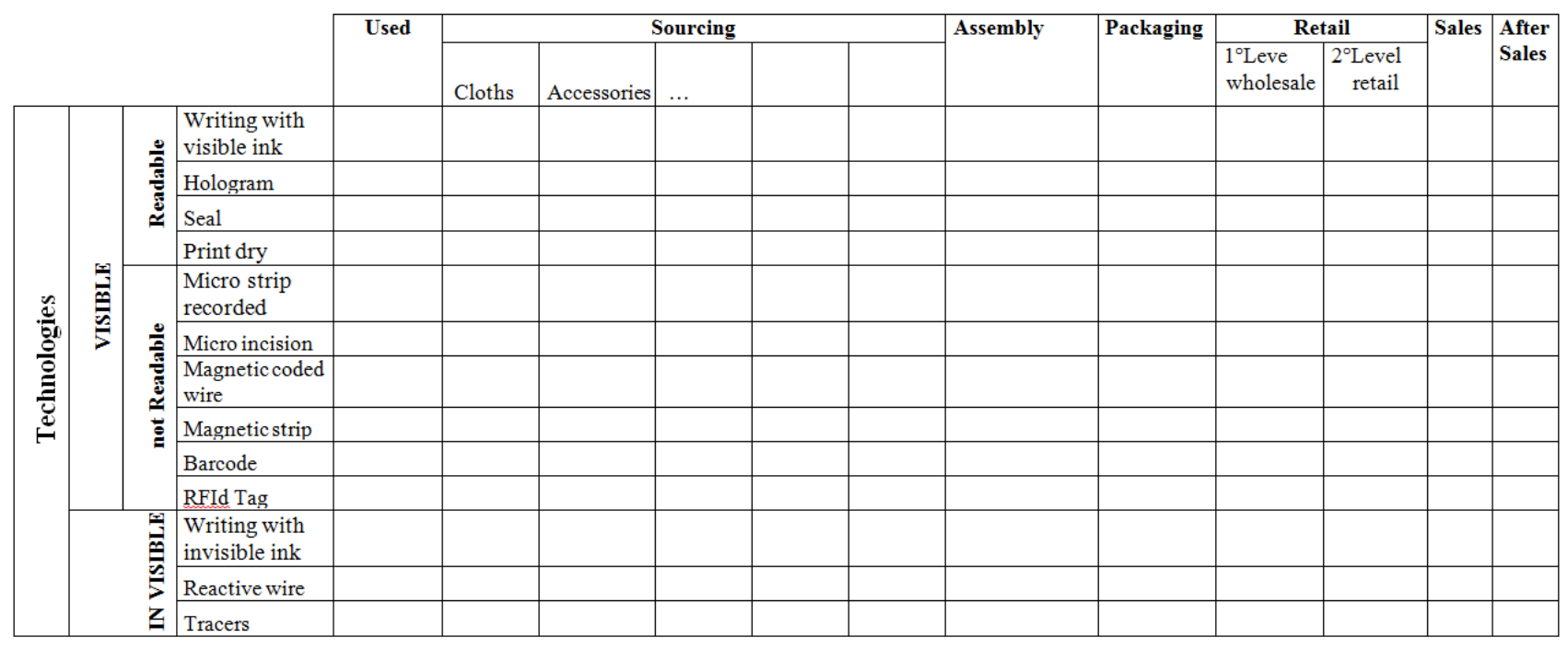

Figure 1 - Evaluation matrix for the application of anti-counterfeiting technologies along the supply chain

Step 3: Cross check of the results obtained in the previous step, in order to detect errors in tool use

The objective of this phase is to find errors due to the improper use of anti-counterfeiting tools by the company. To achieve this purpose, it is necessary to compare the results obtained in the previous phase, evaluating the functionality of the tools with respect to their impact on the authenticity, integrity and traceability of the product.

This way, any contradictions between the purpose for which a particular instrument is used and the performance that is able to offer will be highlighted.

In our case, to achieve this result a comparison between the results obtained in the previous step and the matrix defined above which shows the functionality of the various tools, with respect to the three dimensions of the authenticity definition (intrinsic authenticity, integrity and track and trace), has been done and reported in a textual document.

Step 4: Evaluating the effectiveness of instruments for materials used, the finished product and in relation to the desired level of traceability on the Value Chain. 
In the previous phases the methods and tools used by the company to prevent the counterfeiting phenomenon has been reviewed. Since this step, the method involves an analysis to understand the necessity to introduce new anti-counterfeiting techniques and tools within the company, focusing on the characteristic of the product that has to be developed.

The aim of this phase is to understand the effectiveness of different technologies, applied on different materials, in ensuring product integrity and traceability.

During this step, direct relationship among the company and research laboratory, or directly with anti-counterfeiting tools producers is advised, in order to achieve a better understanding of the results of the application of each instrument at different points of the supply chain.

The template used in the company in order to perform this comparison is reported in Figure 2.

\begin{tabular}{|c|l|l|l|}
\cline { 2 - 4 } \multicolumn{1}{c|}{} & \multicolumn{3}{c|}{ Protection of intellectual property } \\
\hline Technologies & Intrinsic authentication & Integrity & Track and Trace \\
\hline Writing with visible ink & & & \\
\hline Hologram & & & \\
\hline Seal & & & \\
\hline Print dry & & & \\
\hline Micro strip recorded & & & \\
\hline Micro incision & & & \\
\hline Magnetic coded wire & & & \\
\hline Magnetic strip & & & \\
\hline Barcode & & & \\
\hline RFId Tag & & & \\
\hline Tracers & & & \\
\hline Reactive wire & & & \\
\hline
\end{tabular}

Figure 2 - Technologies of the protection of the Intellectual Property

Step 5: Business strategy analysis and anti-counterfeiting tools introduction evaluation

The goal of this step is to compare the product positioning study results, coming from step one, with the company strategy and the possible exploitation of the introduction of anti-counterfeiting tools on the product, or along the supply chain.

Once analyzed the obtained results, the company has all the elements to understand how customers can judge company's initiatives which goal is to improve the security of the product, in comparison with the product positioning perceived by customers and the available solution in the market. Moreover, at this point, taking into account all the possible options, the critical points on which action should be concentrated can be identified by the firm.

In this phase the company has also to identify which aspects of authenticity have to be privileged and which areas of the production processes have to be involved (raw materials, semi-finished or final products production). As a generally rule, it is possible to say that if a company is particularly affected by the presence of false goods, all the initiatives have to be concentrated on the product itself, while, if the phenomenon of the parallel market is more evident, the stage on which the industry will have to act primarily is the distribution.

The output of this phases in our case has been reported using the skeleton of the matrix phase 2 completed for each instrument according to the following rating scale: very good (++), good (+), not good (-); bad (-).

Step 6: Designing for the authenticity and integrity of product.

Having chosen the line to follow, the methodology moves to the phase of product design. This step deals with the development of solutions about the product, designed to ensure the authenticity and integrity. The designer has to take into account the aim to be 
achieved, the compatibility between the technologies used and the chance to involve consumers and the consequences of that choice, as well as the different constraints related to the specific case.

The proposals evaluated at this stage should be critically evaluated by the project team, in terms of feasibility, both technical and managerial, in order to select the solution that best suits the company's requirements and that effectively satisfies the declared goals.

An economic assessment of the selected proposals is also required, to evaluate the profitability of the investment. The company could implement a tool to determine the economic feasibility of the project, explaining the costs and benefits of the new solution and providing an effective support to management decisions.

Finally, should not be overlooked the impact that these solutions could generate on consumers, in order to correctly assess the benefits of the project and avoid negative impacts on customers' perception (i.e. the introduction of the RFiD technology can be interpreted by customers as a violation of their rights in term of privacy).

\section{Step 7: Designing for product traceability.}

The output of step five has defined a strategy to improve product's traceability, along the all supply chain, in order to reduce probability of parallel markets and in order to improve the level of security. According to this strategy, the design for product traceability phase have to outline proposals of process re-engineering and/or regarding the introduction of new technologies, within the constraints of the law (i.e. privacy statement), the type of industry etc.. Focusing on this aspect, in this phase the solution have to improve the supply chain control and visibility, using visible or invisible technologies, in compliance with the normative of every country involved in the product supply chain (i.e. the European normative is different from the American etc..). After defining all the possible solutions, an assessment of them has to be done, with regards both to technical and economic feasibility, as already shown in step six.

All of the steps describe above in the paper can classified according to the conceptual framework of the NPD process, proposed by Bernstien and Macias (Bernstien and Macias, 2002). As reported in Figure 3, the first four steps can be included within the processes of Idea Generation and Idea Screening; step five, six and seven of the DFA within the Concept Development \& Testing, followed by the implementation of the TO BE proposal.

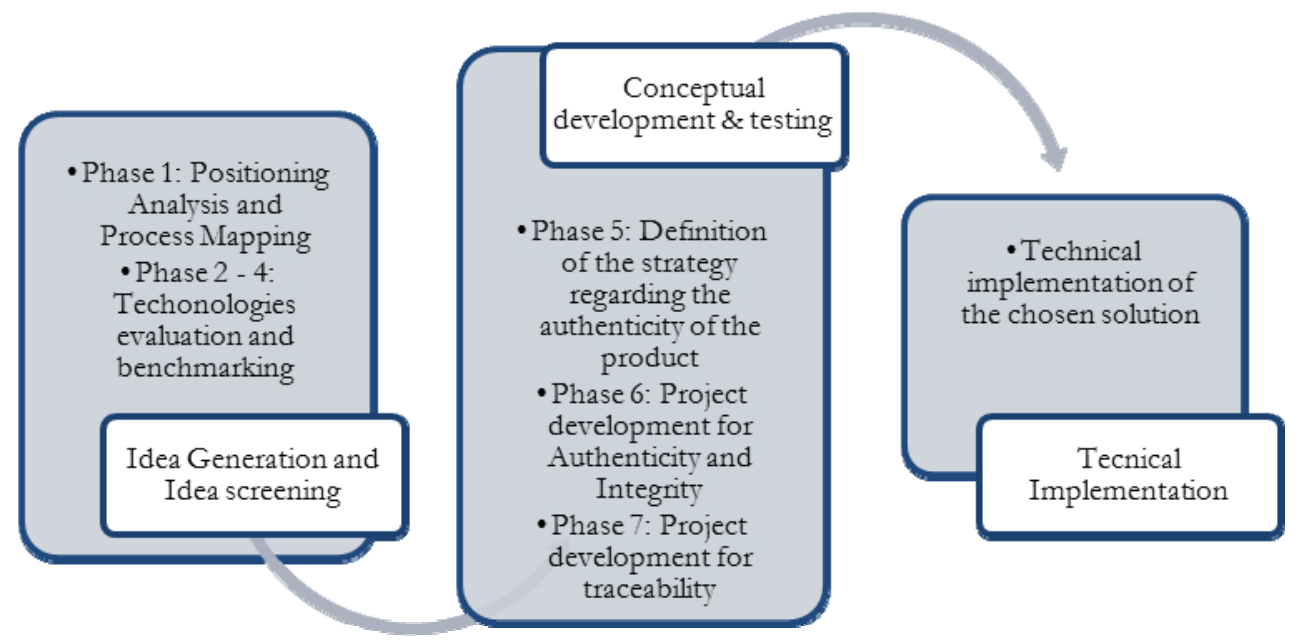

Figure 3 - Phases of the DfA methodology

\section{DfA tools and methods}

One of the most innovative aspects of DfA is the method used to evaluate the product value, presented within step one, and the relationship among product value and authenticity. This issue deserves a quick explanation to understand the connection between these two concepts (product value and authenticity guarantee) and to make clear the reasons which motivated it.

\subsection{Positioning and product value analysis}

As previously written, the assessment of the product value takes place in the first phase of the methodology during the positioning analysis. This study looks at the company's product, first, with respect to the competitive environment, then in relation to its value, and finally explores the perceptions about the phenomenon of fake and the actions to combat it. 


\subsection{Competitor analysis}

The analysis of positioning is expressed primarily through a comparative process, examining the company's product together with the products of its competitors. The first step of this analysis required the identification of the competitors on the market, focusing on those which share the same customer target, offering a product with similar characteristics and the same basic function, and which falls within a comparable price range.

Moreover, special attention should be given to products distributed through the same channels, because of the fact that most frequently customers, during the buying decision process, limited their choice among products which are located in the same market, or within the same channel (i.e. do not compare a product sold through the GDO with a product sold through boutiques).

As a result of this step, for each competitor, a set of dimensions has to been identified. In example, for our test case validation, the selected dimensions have been:

- $\quad$ Price

- Quality

- Style

- Distribution policy

- Position inside the store

- After Sales Customer Services

- Sensitivity to the problems of counterfeiting and brand protection.

These dimension are required in order to perform the product value analysis, as shown hereafter.

\subsection{Product value}

In general, the value of the product depends on many factors:

- Intrinsic value: the product has an intrinsic value, dictated by materials quality, by the design and the performance.

- Value of the brand: the value generated from the customer base who choose that brand will be traduced into brand value and image.

- Value of services: linked to the availability of complementary services, such as the services offered at store level or during the after-sales service.

Especially in the fashion sector, brand equity is an important intangible asset, resulting from the brand recognition (brand awareness), the combination of cognitive and emotional associations linked to the brand in the mind of consumers (brand image) and the customer loyalty to the products of the brand (brand loyalty).

During the assessment of the proposed solution, it is necessary to investigate the value of the product in all its aspects, trying to understand the possible gap between customer perceptions about the attributes related to it and their actual value. More specifically, it's essential to understand the importance attributed to each of the components of value and then assess the performance of the company on such issues, if perceived, actual and expected.

Actual value, expected value and perceived value must be explained in the different dimensions mentioned above, in order to highlight the existence of proportionality between the components. This analysis can be realized by collecting the opinions of consumers first, and then by clarifying the expectations of the company and the actual performance of the product value. Once determined the composition of the product value at different levels, it's possible to assess whether the perceived value by customers is similar with that expected from the company and where are the major differences.

The company has therefore a valuable data about its customers and may use it to review its position and adjust the image that wants to communicate. These information also provide an indication on the actions that a company can implement for the anticounterfeiting. In particular, knowing the importance of different components of the value it is possible to evaluate the benefits of introducing an anti-counterfeiting technique. In fact, the worst damage that affects a company is the one affecting the main dimension of product value and therefore to make an intervention in this direction would lead to the greatest benefit.

For example, if brand value is the main dimension, must be designed the interventions in anti-counterfeiting that are perceived by the customer and that go to increase the prestige of the brand.

\subsection{Perceptions about false and about the interventions to contrast the phenomenon}

A part of the study aims to explore the perception of customers in relation to potential interventions implemented against the various manifestations of the phenomenon of false, from counterfeiting to the gray market, highlighting the type and extent of the impact of such investments on product value.

\section{Methodology validation}

The validation of the DfA methodology has been carried out through a project, sponsored by the LogisLab laboratory, with the cooperation of a well-known Italian fashion company. The case study involved the re-engineering of the specific product "outwear" of a specific brand of the company, which represents the core business of the company itself. 
The project involved the application of the methodology according to the steps described above, starting from the positioning analysis and the study of the value chain. With regard to product positioning, the study was conducted through a survey using a questionnaire, built for the specific product. The time and the resources at our disposal don't allowed us to investigate directly the consumer perception. This way, only the multi-brand store retailers were interviewed. Because of the fact that they are in contact daily with buyers, they can be therefore considered an expression of their opinions. In addition, the survey was restricted to a limited geographic area, with a sample of 30 retailers. Questionnaires were filled through direct interviews, during the collection of orders for the season A/W 2011-12, between January and February 2011.

According to steps six and seven of the methodology proposed in this paper, some proposals to redesign for the protection of the brand and the product traceability have to be suggested. These hypothesis have been developed starting from the state of the art analyzed and presented in the previous step of the methodology, and will be critically evaluated by the company management, in terms of both technical and operational feasibility in order to be able to select the best solution that meets the objectives in the most effective way.

The company where the methodology has been applied belong (Saviolo and Testa, 2005) to the Couture sector. As wrote in the theoretical background, our study will concern mainly with the first two segments, Couture and Prêt-à-porter which can be considered to be included in the Luxury market, where the relationship among the brand value, the perception of counterfeit and customers' intention are evident. Despite this, because of the presence of the tool presented in section 7.3 (product value evaluation), the methodology can be applied to all the sector of the apparel industry. In order to explain this concept, we may suppose to apply the DfA methodology to a product belonging to the mass market. Because of the type of the product, applying the methodology we will find that the presence of fake will not affect in any way the perception and purchase intention of the customers. This way, any investments in anti-counterfeiting technologies will be not profitable, and this way discharged in the steps six and seven.

\section{Conclusions}

The phenomenon of counterfeiting is spreading in an ever more evident way, and to provide a solution in accordance with a structured and systemic plan, that provides suitable solutions to the specific situation of the company, has become a necessity for every firm.

This paper shows that using a single anti-counterfeiting technology to protect a product could not be sufficient, while companies should keep into considerations various aspects of authenticity to achieve a high level of security for their product. Recently, there has been several innovations in the development of new anti-counterfeiting tools, but technology can help both producers than counterfeiters.

The methodology Design for Authenticity is a tool to support companies, which allows to design with the goal of authenticity by following a systematic and structured approach. The proposed methodology aims to identify seven useful steps to analysis and select appropriate anti-counterfeiting technologies to be used at different stages of NPD process and along the Supply Chain (SC), in order to cover all the three aspects of authenticity described above (authenticity, traceability, integrity).

In particular, the methodology is characterized by a starting phase, where a process of information gathering is required. In this phase an understanding of the context, with the evaluation of the efforts already made and of the critical points is conducted. The results of this step provide a robust analysis, from which the type of action required and the understanding of where the resources should be concentrated is understood and planned. This base of information allows also to assess whether or not to pursue a project and which results could lead to the company. In this sense the resources invested in the preliminary study of positioning aren't wasted even if the project of product redesign will not starts or will not completed.

One of the most critical point of the methodology is the evaluation of the so-called To-Be proposal. The use of the Net Present Value (NPV), chosen in this paper in order to determine which solution has to be adopted, is not the only way possible, and maybe nor the best one. The reasons for this assertion lies in the difficulty of estimating the benefits of the investment in a quantitative way, because of the uncertainty in the determination of reliable data regarding the size of the counterfeiting market for the specific product. As a matter of fact, to translate objectively the impact of the new anti-counterfeiting system on the purchasing decisions of consumers (and consequently on the variation of the turnover) is not feasible, even more considering the sphere of perceptions, regarding the value of the brand. Moreover, the illegal nature of the phenomenon prevents the collection of information about counterfeiting and, even if some data exist, they are related to an entire sectors. Companies aren't therefore able to obtain specific data on the counterfeiting of their products. If the first problem is partly recoverable, investigating the positioning and assessing the value with larger customers samples, for the second criticality there are currently no prospects for change.

Future developments could include the use of different assessment methods, both qualitative and quantitative. A qualitative method commonly used for the assessment of development projects is the establishment of a set of questions-filter (screeningquestion) which play a leading role in a comprehensive analysis of the project. Once completed, the checklist may be useful to management for an open discussion on whether and how to implement a project. Finally, as an alternative or in addition to the calculation of the NPV, the Real Option (RO) method could be applied, where the cost of the initial planning of the investment are the option price and the cost of investment is the real cost of exercising the option.

Referring to our methodology, this can be compared to bear the cost to conduct the first steps, exploring the competitive 
environment and assessing the value of the product, and, on the base of the results obtained, to decide whether to complete the investment. In this context, it is possible that the company, after the preliminary study, decides not to implement the initial project, but thanks to the results on the assessment of his company and its product, chooses to achieve different perspectives and to make other types of investments, that could result more attractive.

\section{Acknowledgement}

LogisLab is a laboratory established within the "Polo Universitario Città di Prato" (PIN) structure, which aim is to design and development innovative solutions, rather than to transfer the state-of-the-art best practices to companies, using the knowledge, the instruments and the equipment already present inside the University, or using the experience and the results of its researchers. Logislab, together with its personnel and with the established relationships among the other laboratories and the University itself, is able to assume the role of interdisciplinary skills aggregator, offering a focused “on demand” support to enterprises, local institute and public entities, and to follow these subjects in every steps of their projects, from the idea generation phase, to the fundraising activity, to the project management part.

\section{References}

Aaker, David A., (1996), "Measuring brand equity across products and markets”, California Management Review; Spring 1996; 38, 3; ABI/INFORM Global pp. 102

Amatulli C., Guido G., (2011),"Determinants of purchasing intention for fashion luxury goods in the Italian market: A laddering approach", Journal of Fashion Marketing and Management, Vol. 15 Iss: 1 pp. 123 - 136

Ambler T., (2000), Marketing metrics, Business Strategy Review, 2000, 11 (2), 59-66

Bernsteinn J., Macias D. (2002). “Engineering new product success”. Industrial Marketing Management 31, 51-64.

Bertrand, J.W.M., Fransoo, J.C., (2002). "Modeling and simulation: operations management research methodologies using quantitative modeling”. International Journal of Operations and Production Management 22 (2), 241-254.

Bo Yan; Guangwen Huang; (2008), "Application of RFID and Internet of Things in Monitoring and Anti-counterfeiting for Products," Business and Information Management, 2008. ISBIM '08. International Seminar on , vol.1, no., pp.392-395, 19-19 Dec. 2008, doi: 10.1109/ISBIM.2008.196

Bruce, M., Daly, L., Towers, N., (2004). "Lean or agile. A solution for Supply Chain Management in the textile and clothing industry”. International Journal of Operations and Production Management 24 (2), 151-170.

Brun A., Castelli C., (2008), "Supply chain strategy in the fashion industry: Developing a portfolio model depending on product, retail channel and brand”, International Journal of Production Economics 116 (2008) 169-181

Brun, A., Caniato, F., Caridi, M., Castelli, C., Miragliotta, G., Ronchi, S., Sianesi, A., Spina, G., (2008). “Logistics and supply chain management in the luxury fashion retail: Empirical investigation of Italian firms”. International Journal of Production Economics 114 (2), 554-570.

Chen, L., \& Ko, W. (2008). “A fuzzy nonlinear model for quality function deployment considering Kano’s concept”. Mathematical and Computer Modelling, 48 (3-4), 581-593.

Choy K.L., Chow K.H., Moon K.L., Zeng X., Lau H.C.W., Chan F.T.S., et al. (2008). “A RFID case-based sample management system for fashion product development”. Engineering Applications of Artificial Intelligence, 22(6), 882-896, doi:10.1016/j.engappai.2008.10.011

Christopher M., Lowson R., Peck H., (2004), “Creating agile supply chains in the fashion industry”, International Journal of Retail \& Distribution Management, 32 (8), 367-376

Commission of the European Communities (2005). “On a customs response to latest trends in counterfeiting and piracy”, COM(2005) 479 final.

Coughlan P., Coghlan D., (2002), “Action research for operation management”, International Journal of Operations \& Production Management, 22 (2)

Finn, Angela L. (2011) Luxury fashion: The role of innovation as a key contributing factor in the development of luxury fashion goods and sustainable fashion design. In Onuma, Satochi (Ed.) Conference Proceedings 2011 Fashion \& Luxury: Between Heritage and Innovation, Institut Francais de la Mode (IFM), The Institut Français de la Mode, Paris, pp. 11-18.

Fionda Antoinette M., Moore Christopher M, (2009), “The anatomy of the luxury fashion brand”, Journal of Brand Management 16, 347-363 (March-May 2009) doi:10.1057/bm.2008.45

Forza, C., (2002). "Survey research in operations management: a process-based perspective”. International Journal of Operations and Production Management 22 (2), 152-194.

Gummesson, (2000), “Qualitative method in management research”, (2nd ed.), Sage, Thousand Oaks,CA.

Ibusuki, U., \& Kaminski, P. (2007). "Product development process with focus on value engineering and target-costing: A case study in an automotive company”. International Journal of Production Economics, 105(2), 459-474.

Jeng, A.B.; Li-Chung Chang; Te-En Wei; (2009), "Survey and remedy of the technologies used for RFID tags against counterfeiting," Machine Learning and Cybernetics, 2009 International Conference on , vol.5, no., pp.2975-2981, 12-15 July 
2009, doi: 10.1109/ICMLC.2009.5212582

Keller K.L. (1993), “Conceptualising, measuring and managing customer-based brand equity”, Journal of Marketing, gennaio, 57 (1), 1-22.

Lakafosis, V.; Traille, A.; Lee, H.; Orecchini, G.; Gebara, E.; Tentzeris, M.M.; Laskar, J.; DeJean, G.; Kirovski, D.; (2010), "An RFID system with enhanced hardware-enabled authentication and anti-counterfeiting capabilities," Microwave Symposium Digest (MTT), 2010 IEEE MTT-S International , vol., no., pp.840-843, 23-28 May 2010, doi: 10.1109/MWSYM.2010.5517608

Lee, Y., Sheu, L., \& Tsou, Y. (2008). "Quality function deployment implementation based on Fuzzy Kano model: An application in PLM system”. Computers \& Industrial Engineering, 55(1), 48-63.

Lehtonen, M., Al-Kassab, J., Graf von Reischach, F., Kasten, O., and Michahelles, F., (2007), "Problem-Analysis Report on Counterfeiting and Illicit Trade”. Deliverable D5.1 of EUBRIDGE Project, July 2007.

Lehtonen, M.O.; Michahelles, F.; Fleisch, E.; (2007) , "Trust and Security in RFID-Based Product Authentication Systems," Systems Journal, IEEE , vol.1, no.2, pp.129-144, Dec. 2007,doi: 10.1109/JSYST.2007.909820

Logman M., (2004), “The LOGMAN model: a logical brand management model”, Journal of Product \& Brand Management, 13 (2), 94-104

Moore Christopher M., Doyle Stephen A., (2010),"The evolution of a luxury brand: the case of Prada", International Journal of Retail \& Distribution Management, Vol. 38 Iss: 11 pp. 915 - 927

Morley, Jane, McMahon, Kay (2011) Innovation, interaction, and inclusion: heritage luxury brands in collusion with the consumer. In Fashion \& Luxury : Between Heritage \& Innovation : the 13th Annual Conference for the International Foundation of Fashion Technology Institutes, 11-16 April 2011, Institut Français de la Mode, Paris.

Periaswamy, S.C.G.; Thompson, D.R.; Jia Di; (2011), "Fingerprinting RFID Tags," Dependable and Secure Computing, IEEE Transactions on , vol.8, no.6, pp.938-943, Nov.-Dec. 2011, doi: 10.1109/TDSC.2010.56

Rahman, F.; Ahamed, S.I.; (2012), "Looking for needles in a haystack: Detecting counterfeits in large scale RFID systems using batch authentication protocol," Pervasive Computing and Communications Workshops (PERCOM Workshops), 2012 IEEE International Conference on , vol., no., pp.811-816, 19-23 March 2012, doi: 10.1109/PerComW.2012.6197623

Rajagopal Dr., (2007), "Brand Metrics: a tool to measure performance”, JEL Code: M11, M31, Available at SSRN: http://ssrn.com/abstract=964695

Saviolo S., Testa S., (2005), “Le imprese del sistema moda. Il management al servizio della creatività”, Etas Libri, 2005, ISBN 88453-1303-4

Schilling M.A., (2005), “Innovation Management”, McGraw-Hill 2005

Sen A., (2008), "The US fashion industry: A supply chain review”, International Journal of Production Economics, 114, 571-593

Voss, C., Tsikriktsis, N., Frohlich, M., (2002). "Case research in operations management”. International Journal of Operations and Production Management 22 (2), 195-219.

Westbrook R., (1995), “Action research: a new paradigm for research in production and operations management”, International Journal of Operations \& Production Management, 15 (12), 6-20. ㅇ MCB University Press, 0144-3577

WTO, (2004), "Agreement on Trade-Related Aspects of Intellectual Property Rights”, http://www.wto.org/english/tratop_e/trips_e/t_agm0_e.htm

Yung-Chin Chen; Wei-Lin Wang; Min-Shiang Hwang; (2007), "RFID Authentication Protocol for Anti-Counterfeiting and Privacy Protection," Advanced Communication Technology, The 9th International Conference on , vol.1, no., pp.255-259, 1214 Feb. 2007, doi: 10.1109/ICACT.2007.358350

\section{Biographical notes}

Romeo Bandinelli achieved in 2002 his Bachelor Degree in Mechanical Engineering at Florence University. In 2006 he achieved Ph.D. in Industrial Engineering. He is currently a contract researcher at the Energetic Department of the Engineering Faculty of the University of Florence and responsible of PLM projects for the LogisLab laboratory. He is author of more than 20 papers presented at international scientific conferences. He's an occasional Reviewer for the International Journal of Production Planning and Control, the Journal of Manufacturing Technology Management and Computer \& Industry.

Chiara Pampaloni was born in 1986. In 2011 she graduated with honors in Management Engineering at Florence University. Her research interests are related to the counterfeiting phenomenon in the Luxury Industry. Actually she collaborates with PriceWaterhouseCoopers in the area of System \& Process Assurance.

Rinaldo Rinaldi is associate professor of Supply Chain Management at the University of Florence. He teach "Supply Chain Management“ and "Project Management” for the courses of Mechanical Engineering and Economics. His research areas are related to the logistic systems design and optimization, production planning and control, process optimization. In last years he has been involved in several projects in the area of Track \& Trace and Anti-Counterfeiting technologies for the luxury industry. He is the founder and scientific director of the laboratory of the University of Florence "LogisLab - Laboratory for logistic process management and intelligence systems development."

Received October 2012

Accepted November 2012

Final acceptance in revised form November 2012 